\title{
Plasma etched carbon microelectrode arrays for bioelectrical measurements
}

\section{Heikkinen, Joonas J.}

2018-11

Heikkinen, J J , Kaarela , T , Ludwig , A, Sukhanova , T , Khakipoor , S , Kim , S I , Han , J G , Huttunen , H J , Rivera , C , Lauri , S E , Taira , T , Jokinen , V \& Franssila , S 2018 , ' Plasma etched carbon microelectrode arrays for bioelectrical measurements ' , Diamond and Related Materials , vol. 90 , pp. 126-134 . https://doi.org/10.1016/j.diamond.2018.09.024

http://hdl.handle.net/10138/319672

https://doi.org/10.1016/j.diamond.2018.09.024

cc_by_nc_nd

acceptedVersion

Downloaded from Helda, University of Helsinki institutional repository.

This is an electronic reprint of the original article.

This reprint may differ from the original in pagination and typographic detail.

Please cite the original version. 


\section{Accepted Manuscript}

Plasma etched carbon microelectrode arrays for bioelectrical measurements

Joonas J. Heikkinen, Tiina Kaarela, Anastasia Ludwig, Tatiana Sukhanova, Shokoufeh Khakipoor, Sung Il Kim, Jeon Geon Han, Henri J. Huttunen, Claudio Rivera, Sari E. Lauri, Tomi Taira, Ville Jokinen, Sami Franssila

PII:

S0925-9635(18)30398-4

DOI: doi:10.1016/j.diamond.2018.09.024

Reference: DIAMAT 7213

To appear in: Diamond \& Related Materials

Received date: 8 June 2018

Revised date: 18 September 2018

Accepted date: 22 September 2018

Please cite this article as: Joonas J. Heikkinen, Tiina Kaarela, Anastasia Ludwig, Tatiana Sukhanova, Shokoufeh Khakipoor, Sung Il Kim, Jeon Geon Han, Henri J. Huttunen, Claudio Rivera, Sari E. Lauri, Tomi Taira, Ville Jokinen, Sami Franssila, Plasma etched carbon microelectrode arrays for bioelectrical measurements. Diamat (2018), doi:10.1016/ j.diamond.2018.09.024

This is a PDF file of an unedited manuscript that has been accepted for publication. As a service to our customers we are providing this early version of the manuscript. The manuscript will undergo copyediting, typesetting, and review of the resulting proof before it is published in its final form. Please note that during the production process errors may be discovered which could affect the content, and all legal disclaimers that apply to the journal pertain. 


\title{
Plasma etched carbon microelectrode arrays for bioelectrical measurements
}

\author{
Joonas J. Heikkinen ${ }^{\mathrm{a}, *}$, Tiina Kaarela ${ }^{\mathrm{b}, \mathrm{c}}$, Anastasia Ludwig ${ }^{\mathrm{b}}$, Tatiana Sukhanovab ${ }^{\mathrm{b}}$, Shokoufeh \\ Khakipoor $^{\mathrm{b}}$, Sung Il Kim ${ }^{\mathrm{d}}$, Jeon Geon Han ${ }^{\mathrm{d}}$, Henri J. Huttunen ${ }^{\mathrm{b}}$, Claudio Rivera ${ }^{\mathrm{b}}$, Sari E. \\ Lauri $^{\mathrm{b}, \mathrm{e}}$, Tomi Taira ${ }^{\mathrm{b}, \mathrm{c}}$, Ville Jokinen ${ }^{\mathrm{a}}$, Sami Franssila ${ }^{\mathrm{a}}$ \\ ${ }^{a}$ Department of Chemistry and Materials Science, Aalto University, Finland \\ Micronova, Tietotie 3, 02150 Espoo \\ ${ }^{b}$ Neuroscience Center, University of Helsinki, Finland \\ Viikinkaari 4, 00790 Helsinki \\ ${ }^{c}$ Department of Veterinary Biosciences, University of Helsinki, Finland \\ Agnes Sjöberginkatu 2, 00014 Helsinki \\ ${ }^{d}$ Center for Advanced Plasma Surface Technology (CAPST), Sungkyunkwan University, Republic of Korea \\ 300, Cheoncheon-dong, Jangan-gu, Suwon-si, Gyeonggi-do \\ ${ }^{e}$ Department of Biosciences, University of Helsinki, Finland \\ Viikinkaari 1, 00014 Helsinki
}

\begin{abstract}
Carbon-based materials have attracted much attention in biological applications like interfacing electrodes with neurons and cell growth platforms due to their natural biocompatibility and tailorable material properties. Here we have fabricated sputtered carbon thin film electrodes for bioelectrical measurements. Reactive ion etching (RIE) recipes were optimized with Taguchi method to etch the close field unbalanced magnetron sputtered carbon thin film (nanocarbon, $\mathrm{nC}$ ) consisting of nanoscale crystalline $\mathrm{sp}^{2}$-domains in amorphous $\mathrm{sp}^{3}$-bonded backbone. Plasma etching processes used gas mixtures of $\mathrm{Ar} / \mathrm{O}_{2} / \mathrm{SF}_{6} / \mathrm{CHF}_{3}$ for $\mathrm{RIE}$ and $\mathrm{O}_{2} / \mathrm{SF}_{6}$ for ICP-RIE. The highest achieved etch rate for nanocarbon was $\gg 389 \mathrm{~nm} / \mathrm{min}$ and best chromium etch mask selectivity was 135:1. Biocompatibility of the material was tested with rat neuronal cultures. Next, we fabricated multielectrode arrays (MEA) with carbon recording electrodes and metal wiring. Organotypic brain slices grown on the MEAs were viable and showed characteristic spontaneous electrical network activity. The results demonstrate that interactions with nanocarbon substrate support neuronal survival and maturation of functional neuronal networks. Thus the material can have wide applications in biomedical research.
\end{abstract}

Keywords: carbon, reactive ion etching, ICP-RIE, multielectrode array, neurons, neuronal networks

\footnotetext{
${ }^{*}$ Corresponding author

Email addresses: joonas.heikkinen@aalto.fi (Joonas J. Heikkinen), tel. +358 405616872 (Joonas J. Heikkinen), tiina.kaarela@helsinki.fi (Tiina Kaarela), anastasia.ludwig@gmail.com (Anastasia Ludwig), tat.sukhanova@gmail.com (Tatiana Sukhanova), shokoufeh.khakipoor@anat.uni-freiburg.de (Shokoufeh Khakipoor), sish.kim2010@gmail.com (Sung Il Kim), hanjg5445@gmail.com (Jeon Geon Han), Henri.Huttunen@helsinki.fi (Henri J. Huttunen), claudio.rivera@helsinki.fi (Claudio Rivera), Sari.Lauri@helsinki.fi (Sari E. Lauri), tomi.taira@helsinki.fi (Tomi Taira), ville.p.jokinen@aalto.fi (Ville Jokinen), sami.franssila@aalto.fi (Sami Franssila)
} 


\section{Introduction}

Carbon has showed a great promise as an electrode material, since it is naturally biocompatible and the material properties can be tailored over a wide range by controlling the crystallinity and hybridization. Novel carbon materials and microfabricated carbon structures developed during past 20 years offer distinct properties when compared to a sheet of graphitic carbon, which has been used as an electrochemical electrode since early 1990s [1]. Possibility to create thin films (thicknesses in nanometer and micrometer scale) has produced a wealth of new carbon materials: amorphous carbon (a-C), diamond like carbon (DLC), tetrahedral amorphous carbon (ta-C) and (ultra)nanocrystalline diamond ( $\mathrm{uNCD}$ ). Carbon materials provide unique combination of chemical, electrical, mechanical, and thermal properties for biological electrochemistry, as carbon has structural polymorphism [2, p. 389; 3], is chemically stable [4], has good corrosion resistance [2, p. $388 ; 3 ; 5]$, has rich surface chemistry [2, p. 86-173], has good electrical conductivity [3], and it can create strong bonds both internally and with a surface modifier [1].

Sputtered carbon with $\mathrm{sp}^{2}$ nanodomains, called nanocarbon $(\mathrm{nC})$, is one of the newly found and characterized carbonaceous materials [4]. $\mathrm{nC}$ can be deposited in multiple ways, like electron cyclotron resonance chemical vapor deposition (ECR-CVD), DC- and RF-plasma enhanced chemical vapor deposition (PECVD), and close field unbalanced magnetron (CFUBM) sputtering $[4,5]$. In ternary phase diagram for amorphous carbon-hydrogen system, nanocarbon is located on the line between $\mathrm{sp}^{2}$ and $\mathrm{sp}^{3}$, roughly the same region as ta-C. [6] Depending on the ratio of $\mathrm{sp}^{3}$ and $\mathrm{sp}^{2}$ regions, material properties (like electrical conductivity from semiconducting to insulating) can be varied $[7,8]$. Such a biocompatible material with a good electrical conductivity is an ideal material for electrodes, which are meant for biosignal measurements in a non-invasive manner.

For bioelectrical devices, many other aspects besides the materials must be considered; structural layout, insulation, recording/output electrodes, vulnerability to electric noise or interference, and patterning. Pyrolytic carbon films fabricated from photoresist offer a method for fabricating micropatterned carbon structures [9]. Pyrolytic carbon has been used in batteries [1], stem cell differentiation [10], and as an electrochemical detector for dopamine [10, 11] and paracetamol [11]. However, creating patterns and features in carbon thin films is not a straightforward process, as they are chemically inert. Therefore, wet etching of these films is not possible, and dry etching methods must be used [12]. Focused ion beam (FIB) etching can be used to make grooves and patterns into carbon films, but it is expensive and slow (serial process). Micropattern fabrication is required for eletrodes which has features as small as the cell size.

Multielectrode arrays (MEAs) are devices containing multiple microscale electrode plates or needles to record bioelectrical activity from a living tissue $[13,14,15,16]$. MEAs are used in biomedical research to record extracellular electrical activity simultaneously from multiple locations e.g. in cardiac muscle or neural tissue. MEA devices can be used in in vitro like in brain slice 
studies $[13,14]$ or in vivo, where the array is implanted directly into the brain (also known as microprobes or penetrating electrodes [17]). The key advantage in planar MEA-method is the possibility to culture the tissue of interest on MEA and to do parallel recordings of electrical activity over a long periods of time. The number of recording electrodes can vary from less than 20 [18] to over 59000 [19]. Also, MEAs are widely used in high-throughput screening of drug effects in cellular cultures [20]. Moreover, even individual neurons can be grown on MEA [21] by utilizing microfluidic channels [22], allowing combined optical and electrical characterization of subcellular activity.

In order to utilize carbon thin films in multielectrode arrays, it is essential to understand the reaction chemistry behind ion etching. Tetrahedral amorphous carbon (similar composition as nanocarbon) can be etched in oxygen plasma [12, 23, 24]. The proposed reason for this is that when high energy $\mathrm{O}^{+}$-ions collide into carbon atoms, the strong carbon bonds break, and the released $\mathrm{C}$-atoms create new bonds with available oxygen ions, and the resulting reaction products are $\mathrm{CO}_{2}$ and $\mathrm{CO}$ [24]. Argon has an important role in enhancing the ion etching process, as it provides more energy to the etched surface, and can produce sputter etching. When $\mathrm{CHF}_{3}$ is used as an etching gas, hydrogen and fluorine are introduced into the chamber. $\mathrm{F}^{+}$will react with $\mathrm{C}$ along with oxygen to form $\mathrm{COF}_{2}$. On the carbon substrate, $\mathrm{F}^{+}$-ions can form $\mathrm{C}_{2} \mathrm{~F}_{4}$. $\mathrm{H}$ can form hydrocarbons together with $\mathrm{C}$, but it can also react with $\mathrm{F}$ and create hydrofluoric acid, which can be pumped out. When $\mathrm{SF}_{6}$ is used along $\mathrm{O}_{2}$ and $\mathrm{Ar}$, the reaction products with carbon are most probably $\mathrm{CO}, \mathrm{CO}_{2}, \mathrm{C}_{2} \mathrm{~F}_{4}$, and $\mathrm{COF}_{2}$ [25]. $\mathrm{SF}_{6}$ can be broken into $\mathrm{SF}_{4}{ }^{2+}$ and $\mathrm{SF}_{2}{ }^{4+}$ with ionization, which then can react with oxygen to form $\mathrm{SOF}_{4}$ and $\mathrm{SO}_{2} \mathrm{~F}_{2}$ [26]. These formed gases can be pumped out of the system, as they will not react with carbon substrate. Therefore, $\mathrm{SF}_{6}$ is a good source for fluorine, as $\mathrm{F}^{+}$-ions will react vigorously with $\mathrm{C}$-atoms on the substrate.

Here we have used RIE and ICP-RIE processes for patterning nanocarbon films to create $8 \times 8$ planar MEAs. Nanocarbon possess many beneficial properties for neuronal studies (like electrochemical detection of neurotransmitter dopamine [27] and controllable electrical conductivity $[7,8])$, but due to its robust nature it has not been micropatterned until now. A comparison between the plasma etching parameters, and the etch rate and selectivity was done. Biocompatibility and signal detection properties of the nanocarbon MEAs were investigated using neuronal cultures and organotypic hippocampal slices.

\section{Experimental}

Successful fabrication of a carbon multielectrode array (C-MEA) requires microfabrication techniques such as lithography, plasma etching, wet etching, sputtering, and chemical vapor deposition. From all the techniques, only the plasma etching processes were optimized in this research. Because etching gases/ions have plethora possible reaction mechanisms and the ion etching equipment have 
multiple adjustable parameters, it is crucial to identify the effect of all variables.

Two plasma etching techniques were used to etch nC: RIE and ICP-RIE, and chromium was used as an etch mask in both experiments. Taguchi-method orthogonal arrays $\mathrm{L}_{8}\left(2^{5}\right)$ and $\mathrm{L}_{8}\left(2^{6}\right)$ $[28,29]$ were used for designing of experiments for RIE and ICP-RIE, respectively. Response value $\Delta$ for $\mathrm{nC}$ and $\mathrm{Cr}$ etch rates is calculated for all parameters by subtracting each factors etch depth minimum level from etch depth maximum level. Signal-to-noise $(\mathrm{S} / \mathrm{N})$ ratios were calculated for all parameters and compared to determine which affect most to the etching process. S/N ratio for $\mathrm{nC}$ is calculated with larger-is-better formula, and $\mathrm{S} / \mathrm{N}$ for $\mathrm{Cr}$ with smaller-is-better.

\subsection{Nanocarbon deposition}

The carbon thin film is deposited with CFUBM sputtering, where the substrate (oxidized 100 $\mathrm{mm}$ silicon wafer) is placed in the center of magnetic field while the sputtering targets are near the north and south poles of the magnet $[4,30]$. The deposition of $\mathrm{nC}$ film on top of silicon substrate is explained in more detail in [4] and [5]. During deposition, two graphite (99.999\% purity, diameter $10.16 \mathrm{~cm}$ ) targets were bombarded with argon (99.999\% purity, gas flow $80 \mathrm{sccm}$ ) with constant power density of $30 \mathrm{~W} / \mathrm{cm}^{2}$. The substrate was heated to $150{ }^{\circ} \mathrm{C}$, rotated $10 \mathrm{rpm}$, the base pressure before deposition was $2.6^{*} 10^{-3} \mathrm{~Pa}$ and the working pressure during deposition $0.4 \mathrm{~Pa}$, bias voltage was $-50 \mathrm{~V}$ and distance between the substrate and the target $60 \mathrm{~mm}$.

\subsection{Nanocarbon patterning}

Mask

$80 \mathrm{~nm}$ thick chromium thin film served as a hard mask for $\mathrm{nC}$ etching. Cr was deposited by sputtering (Plasmalab 400, Oxford Instruments) on a $100 \mathrm{~mm}$ silicon wafer. The mask pattern was transferred on the chromium film with optical lithography and wet etching. First, the $\mathrm{Cr}$ film was treated with HMDS (hexamethyldisilazane) adhesion promoter and then spin coated with photoresist AZ5214 (MicroChemicals). The resist was soft baked in $90{ }^{\circ}$ for two minutes on a hotplate followed by UV-exposure through a plastic photomask for three seconds. The exposed film was developed in AZ351B developer (MicroChemicals) for one minute, then rinsed in DI-water for four minutes and dried with a spindryer. Development process removed the exposed parts of the resist. The resulting structures were hard baked in $120^{\circ}$ for three minutes to evaporate remaining solvent from the resist. The chromium layer was etched through AZ5214 mask in 3:1:21 $\mathrm{Ce}\left(\mathrm{NH}_{4}\right)_{2}\left(\mathrm{NO}_{3}\right)_{6}: \mathrm{HClO}_{4}: \mathrm{H}_{2} \mathrm{O}$ solution (MicroChemicals) in room temperature approximately 90 seconds and rinsed with DI-water for five minutes and dried with a nitrogen gun. The resist was removed in an ultrasound assisted acetone bath for 10 minutes, then rinsed with clean acetone and isopropyl alcohol and finally with DI-water, followed by spindrying.

The wafer was cleaved into smaller pieces: $1 \times 1.5 \mathrm{~cm}^{2}$ for RIE and $1 \times 3 \mathrm{~cm}^{2}$ for ICP-RIE. The Cr mask coverage varied between the samples: $0.54,0.65,0.83$ and $0.98 \mathrm{~cm}^{2}$ with RIE samples and 
1.19 and $1.80 \mathrm{~cm}^{2}$ with ICP-RIE samples. This causes different loading during etching process.

Reactive ion etching

RIE was carried out with Oxford Instruments Plasmalab 80Plus. Etching parameters with two levels were plasma power: 40 and $80 \mathrm{~W}$, gas flows: $\mathrm{O}_{2} 20$ and $40 \mathrm{sccm}, \mathrm{SF}_{6} 40$ and $80 \mathrm{sccm}, \mathrm{CHF}_{3}$ 40 and $80 \mathrm{sccm}$ and pressure: 50 and 100 mTorr. Temperature was kept in room temperature and argon flow in $80 \mathrm{sccm}$ at all experiments. The etch time in every experiment was two minutes.

\section{Inductively coupled plasma reactive ion etching}

The ICP-RIE was carried out with Oxford Instruments Plasmalab System100 - ICP 180 and parameters with two levels were temperature: -110 and $20^{\circ} \mathrm{C}$, ICP power: 200 and $500 \mathrm{~W}$, RF power: 100 and $150 \mathrm{~W}$, gas flows: $\mathrm{O}_{2} 10$ and $40 \mathrm{sccm}, \mathrm{SF}_{6} 10$ and $40 \mathrm{sccm}$ and pressure: 10 and 15 mTorr. ICP-power refers to the inductive coil power, and RF-power to the power applied to wafer electrode (which is responsible for ion bombardment). The etch time in every experiment was two minutes.

\subsection{Nanocarbon characterization}

Raman analysis

Raman spectroscopy of nanocarbon film was performed with WITec Alpha 300 RA. Line scan was used with the following parameters: line length $3 \mathrm{~mm}$, points in line 50, accumulations per point 10, integration time $0.5 \mathrm{~s}$. Green $532 \mathrm{~nm}$ laser was used, and seven $\mathrm{nC}$ samples were analyzed. Results were analyzed with OriginLab data analysis software. Peaks were fitted with Breit-WignerFano $(\mathrm{BWF})+$ Lorentz -formula, and $\mathrm{I}_{\mathrm{D}} / \mathrm{I}_{\mathrm{G}}$ ratio was calculated by comparing the height of fitted peaks, as recommended by [31].

\section{Profilometry}

The etched feature depths were measured with Bruker Dektak XT stylus profilometer. Feature thicknesses were measured before etching (Cr mask thickness), after etching, and after removing $\mathrm{Cr}$ etch mask. This allowed the calculation of etch rates for both $\mathrm{nC}$ and $\mathrm{Cr}$. Results were analyzed with Minitab 17 statistical software and mean effect values were calculated to determine which parameters had the biggest effect on the etching process.

\section{Electrical characterization}

The resistance of $\mathrm{nC}$ films was measured with four-point probe (CPS probe station, Cascade Microtech with Keithley 2000 multimeter). The sheet resistance and resistivity values for nanocarbon were calculated from the resistance values. 


\subsection{Multielectrode array}

Several multielectrode arrays were fabricated from multiple recording electrode - wiring metal material combinations. The recording electrodes were fabricated either from aluminum, chromiumplatinum or nanocarbon, from which aluminum and chromium-platinum electrodes were for reference. Used wiring metals for nanocarbon electrodes were either aluminum or chromium. Electrodes were insulated either with silicon oxide or photoresist SU-8 The geometry of the MEA mimics the commercial MED64-P515A -MEA [32], by having 8x8 array of recording electrodes (50x50 $\mu^{2}$ squares) separated with xy-distance of $250 \mu \mathrm{m}$ and $450 \mu \mathrm{m}$. The MEA chip is $5 \times 5 \mathrm{~cm}^{2}$ square, and the recording electrodes were wired to outer edge of the chip to connect to $1 \times 6 \mathrm{~mm}^{2}$ output electrodes.

The conducting $\mathrm{nC}$ thin film was deposited on a thermally oxidized silicon wafer. Nanocarbon patterns were defined by optical lithography and dry etching with $\mathrm{Cr}$ as hard mask. After dry etching, an insulating layer was deposited: either silicon oxide or SU-8 2000.5. Silicon oxide layer (100-200 nm) was deposited with PECVD (Plasmalab 80Plus, Oxford Instruments) and insulation openings were done on both ends of the electrodes with optical lithography and RIE. Photoresist AZ5214 served as an etching mask in RIE of silicon oxide with parameters: plasma power $200 \mathrm{~W}$, gas flows $\mathrm{CHF}_{3} 25 \mathrm{sccm}$, Ar $25 \mathrm{sccm}$, pressure 30 mTorr and temperature in room temperature with etch rate of $35 \mathrm{~nm} / \mathrm{min}$. If SU-8 2000.5 (800 nm) was used as an insulation layer, it was spin coated with $3000 \mathrm{rpm}$ for 30 seconds and soft baked in $95{ }^{\circ} \mathrm{C}$ for three minutes. Then it was exposed to UV-light for six seconds followed by post exposure bake in $95{ }^{\circ} \mathrm{C}$ for five minutes. Final structures were created during development in SU-8 Developer (MicroChem) for 25 seconds. Cr was removed from the recording electrodes with 3:1:21 $\mathrm{Ce}\left(\mathrm{NH}_{4}\right)_{2}\left(\mathrm{NO}_{3}\right)_{6}: \mathrm{HClO}_{4}: \mathrm{H}_{2} \mathrm{O}$ wet etching in room temperature for approximately 90 seconds. If $\mathrm{Al}$ was used as a conducting wire, it was removed from the recording electrodes with 80:4:16 $\mathrm{H}_{3} \mathrm{PO}_{4}: \mathrm{HNO}_{3}: \mathrm{H}_{2} \mathrm{O}$ in $50{ }^{\circ} \mathrm{C}$ for one minute. MEA device was diced from the silicon wafer into $5 \times 5 \mathrm{~cm}^{2}$ piece with a Loadpoint Microace 3 dicing saw, and a quartz ring was glued with polydimethylsiloxane (PDMS) to serve as a cultivation well.

\subsection{Neuron growth and brain slice experiments}

To test the viability of a dissociated neuronal culture on nanocarbon $(\mathrm{nC})$ material, $\mathrm{nC}$ and reference glass coverslips were coated with poly-D-Lysine. Rat embryonic hippocampal neurons (Wistar rats, E17) were cultivated for seven days on both samples at a density of 150000 cells $/ \mathrm{cm}^{2}$. More detailed culturing and preparation process is described elsewhere by [33]. Primary antibodies (rabbit anti-KCC2 (1:2 000 dilution), mouse NeuN (1:400 dilution, Milipore), mouse anti-MAP2 (1:500 dilution, Chemicon) and rabbit anti-GFAP (1:400 dilution, Chemicon)) were diluted to the final concentration in $2 \%$ serum / $0.1 \%$ Triton X-100 / PBS for staining experiments. Next day samples were incubated with secondary antibodies (anti-rabbit Alexa Fluor 488 and antimouse Alexa Fluor 568, both from Molecular Probes at 1:400 dilution), washed and mounted in 
Prolong Gold mounting media (Life Technologies). Fluorescent wide-field images were acquired with Zeiss AxioImager M1 microscope equipped with AxioCam HR camera and 40x objective ECPlan-Nerofluar/0.75/Ph2. The fluorescence was evaluated using ImageJ program. Cells were defined as ROI (region of interest) and the intensity of signal was measured.

Organotypic hippocampal slice cultures were made for nC MEA testing. Before use, MEAs were sterilized with $70 \%$ ethanol for one hour, washed with sterile water and dried under UV-light for one hour. For adhesive coating, MEAs were treated over night with sterilized polyethylenimine solution ( $0,1 \%$ polyetylenimine in $25 \mathrm{mM}$ Borate buffer). Protocol for organotypic slices was derived from [34]. $400 \mu \mathrm{m}$ slices of hippocampus were dissected from P7 Wistar rat pups and transferred onto MEAs. The slices were cultivated in $250 \mu \mathrm{l}$ of culture medium (Neurobasal A (Gibco), 2 \% B27-supplement (Gibco), 2 mM L-glutamine, and chloramphenicol). Cultures were maintained in humidified cell culture incubator $\left(+35{ }^{\circ} \mathrm{C}, \mathrm{CO}_{2} 5 \%\right)$, on a rocking stage. The culture media was changed every second day and activity recordings were made after eight days in vitro (DIV8). First, spontaneous activity of the organotypic slice cultures was recorded for ten minutes after 30 minutes of stabilization. After baseline recording $2 \mathrm{nM}$ tetrodotoxin (TTX) was added into the media and recording was repeated. All the recordings were done in a recording incubator with the cell culture environment $\left(35^{\circ} \mathrm{C}, \mathrm{CO}_{2} 5 \%\right)$. After 10DIV the slice cultures were treated over night with propidium iodide (Sigma Aldrich) for quantification of dead cells. Cultures were imaged with Leica MZ10F microscope and Qimaging Rolera Bolt Scientific camera. Images were analyzed and processed with ImageJ software.

Recordings were done with MED64 system (Alpha MED Scientific): MED 64-amplifier (MEDA64HE1, Alpha MED Scientific) and the data was collected with Mobius Software (Alpha MED Scientific) using a low cut frequency of $0,1 \mathrm{~Hz}$, high cut frequency of $10000 \mathrm{~Hz}$, input range $5 \mathrm{mV}$ and a sampling rate of $20000 \mathrm{~Hz}$. The data obtained using nC MEAs were compared with data collected using commercial MED64 MED-P515A MEAs with platinum black recording electrodes and indium tin oxide wiring. Acquired data was analyzed with Spike2 (CED) software. For the analysis, the mains-related $50 \mathrm{~Hz}$ interference was subtracted from the signal by using the hum removal algorithm in Spike2 and the recorded traces were offset to zero with DC remove time constant 5s. The work has been carried out in accordance with Directive 86/609/EEC for animal experiments.

\section{Results and discussion}

\subsection{Etching results}

Nanocarbon was succesfully etched with both plasma etching methods. Clear differences with the etch rates were observed between the processes, but also between the recipes within a process. The results are presented below with analysis. The etched samples had different loadings during 
etching, but the effect of this was considered insignificant due to only a small variations in surface areas between the samples. Also, the size of reaction chamber and the used glas flows and pressure were considered big/high enough to cover these small variations in the surface area, therefore the loading has not been take into account in following calculations.

\subsubsection{RIE}

The RIE etch rates of $\mathrm{nC}$ and $\mathrm{Cr}$ with Taguchi orthogonal array method are shown in Table 1. Signal-to-noise $(\mathrm{S} / \mathrm{N})$ ratios were calculated for all parameters to find out which RIE parameter affects the etching most.

Table 1: Taguchi $\mathrm{L}_{8}\left(2^{5}\right)$ orthogonal array with two levels for RIE results. All experiments were done in room temperature, and argon flow was kept in $80 \mathrm{sccm}$ in most experiments. Experiment "Max" was done with $50 \mathrm{sccm}$ Ar flow.

\begin{tabular}{|c|c|c|c|c|c|c|c|c|c|c|}
\hline \multirow[t]{2}{*}{$\begin{array}{c}\text { Expt. } \\
\text { No. }\end{array}$} & \multirow[t]{2}{*}{$\begin{array}{l}P \\
W\end{array}$} & \multicolumn{3}{|c|}{$\begin{array}{l}\text { Gas Flow } \\
\text { sccm }\end{array}$} & \multirow[t]{2}{*}{$\begin{array}{l}\text { Pres. } \\
\text { mTorr }\end{array}$} & \multicolumn{2}{|c|}{$\begin{array}{c}\text { Etch rate } \\
\mathrm{nm} / \mathrm{min}\end{array}$} & \multirow[t]{2}{*}{$\begin{array}{l}\text { Selec- } \\
\text { tivity }\end{array}$} & \multicolumn{2}{|c|}{$\begin{array}{l}S / N \\
d B\end{array}$} \\
\hline & & $\mathrm{O}_{2}$ & $\mathrm{SF}_{6}$ & $\mathrm{CHF}_{3}$ & & $\mathrm{nC}$ & $\mathrm{Cr}$ & & $\mathrm{nC}$ & $\mathrm{Cr}$ \\
\hline 1 & 40 & 20 & 40 & 40 & 50 & 4.7 & 0.9 & $5: 1$ & 13 & 1 \\
\hline 2 & 40 & 20 & 40 & 80 & 100 & 1.7 & 2.7 & $1: 2$ & 5 & -9 \\
\hline 3 & 40 & 40 & 80 & 40 & 50 & 3.9 & 2.4 & $2: 1$ & 12 & -8 \\
\hline 4 & 40 & 40 & 80 & 80 & 100 & 2.3 & 2.3 & $1: 1$ & 7 & -7 \\
\hline 5 & 80 & 20 & 80 & 40 & 100 & 4.6 & 0.1 & $36: 1$ & 13 & 18 \\
\hline 6 & 80 & 20 & 80 & 80 & 50 & 8.5 & 1.7 & $5: 1$ & 19 & -4 \\
\hline 7 & 80 & 40 & 40 & 40 & 100 & 7.5 & 3.9 & $2: 1$ & 18 & -12 \\
\hline 8 & 80 & 40 & 40 & 80 & 50 & 13.4 & 7.7 & $2: 1$ & 23 & -18 \\
\hline$\Delta_{\mathrm{nc}}$ & 5.4 & 1.9 & 2.0 & 1.3 & 3.6 & & & & & \\
\hline$\Delta_{\mathrm{cr}}$ & 1.3 & 2.7 & 2.1 & 1.7 & 0.9 & & & & & \\
\hline Opt.nc & 80 & $\overline{40}$ & 40 & 80 & 50 & 14.0 & 0.7 & $20: 1$ & 32 & -11 \\
\hline Opt.sel & 80 & 40 & 80 & 40 & 50 & 12.1 & 0.3 & $40: 1$ & 31 & -38 \\
\hline Max & 200 & 50 & 0 & 0 & 30 & 92.7 & 2.1 & $44: 1$ & 45 & -15 \\
\hline
\end{tabular}

For an optimal etching recipe, the nanocarbon etch rate must be high but also the selectivity between $\mathrm{nC}$ and $\mathrm{Cr}$ must be high to avoid chromium sputtering and redeposition. Figure 1 shows the response diagram of each parameter to $\mathrm{nC}$ and $\mathrm{Cr}$ etch rate. To calculate the $\Delta$-value presented in Table 1, the lower level must be subtracted from the higher one. The steepness of the slope indicates which parameters have the greatest impact on etch rate. For high $\mathrm{nC}$ etch rate power should be high and pressure low. The effect of gas flows is smaller.

Experiments 6 and 8 show the highest etch rates for $\mathrm{nC}$. Selectivities between $\mathrm{nC}$ and $\mathrm{Cr}$ are mostly poor, except in the experiment number 5 . Best responses for higher $\mathrm{nC}$ etch rate are with high level power, low level pressure, and low level $\mathrm{SF}_{6}$ flow rate. For Cr etching, the most effective parameters are high level $\mathrm{O}_{2}$ flow rate, low level $\mathrm{SF}_{6}$ flow rate, and high level $\mathrm{CHF}_{3}$ flow rate. To find improved recipe, the most critical parameters for $\mathrm{nC}$ should be maximized and for $\mathrm{Cr}$ they should be minimized. Therefore, two recipes were created with two parameter levels: optimal for 
Main effects plot for mean values

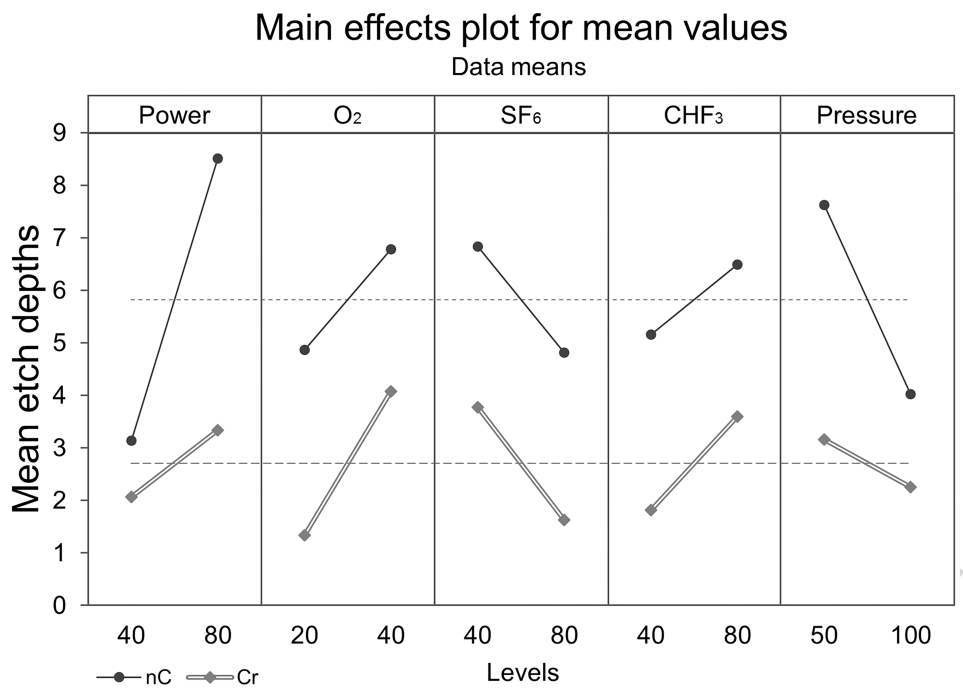

Figure 1: Response diagram of Taguchi experiments for both $\mathrm{nC}$ and $\mathrm{Cr}$ with reactive ion etching. $\mathrm{nC}$ and $\mathrm{Cr}$ trends are similar, but power and pressure effects are substantially bigger for $\mathrm{nC}$.

$\mathrm{nC}$ etching (Opt.nC) and optimal for high selectivity (Opt.Sel). Last recipe "Max" was created to maximize the $\mathrm{nC}$ etch rate within equipment parameter boundaries.

As can be seen from Table 1, the Opt.nC recipe has the same parameter levels as experiment number 8 , and $\mathrm{nC}$ etch rate is similar. Recipe Opt.Sel has lower etch rate for $\mathrm{nC}$ than Opt.nC, but two fold better selectivity. Recipe "Max" was used with high power and 1:1 Ar: $\mathrm{O}_{2}$ gas mixture. Our result is in accordance with [35] who reports Ar: $\mathrm{O}_{2}$ gas mixture has a good etch rate $(\sim 50$ $\mathrm{nm} / \mathrm{min}$ ) for diamond. In addition to good etch rate, also a good selectivity was obtained with only oxygen as a reactive gas.

\subsubsection{ICP-RIE}

ICP-RIE etching results with Taguchi orthogonal array method are shown in Table 2 with $\mathrm{S} / \mathrm{N}$-ratios for all parameters.

Figure 2 shows the response diagram of each parameter to $\mathrm{nC}$ and $\mathrm{Cr}$ etch rate. As can be seen from the slopes, ICP power has by far the greatest effect on $\mathrm{nC}$ etch rate. Temperature, $\mathrm{RF}$-power and $\mathrm{SF}_{6}$ flow show hardly any effect.

ICP-RIE experiments 4 and 8 show the highest etch rates for $\mathrm{nC}$, but best selectivities were obtained with recipes 1 and 3 . The highest responses for $\mathrm{nC}$ etch rate are with high level ICPpower, low level pressure, and high level oxygen flow. For Cr etching, the most effective parameters are low level pressure, high level ICP-power, and high level oxygen flow. To find out the best recipe, the most critical parameters for $\mathrm{nC}$ should be maximized and for $\mathrm{Cr}$ they should be minimized. Therefore, two recipes were created with two parameter levels: optimal for $\mathrm{nC}$ etching (Opt.nC) and optimal for high selectivity (Opt.sel). Last recipe "Max" was created to maximize the nC etch 
Table 2: Taguchi $\mathrm{L}_{8}\left(2^{6}\right)$ orthogonal array for ICP-RIE results.

\begin{tabular}{|c|c|c|c|c|c|c|c|c|c|c|c|}
\hline \multirow[t]{2}{*}{$\begin{array}{l}\text { Expt. } \\
\text { No. }\end{array}$} & \multirow[t]{2}{*}{$\begin{array}{l}\mathbf{T} \\
{ }^{\circ} \mathbf{C}\end{array}$} & \multicolumn{2}{|c|}{$\begin{array}{c}\text { Power } \\
\text { W }\end{array}$} & \multicolumn{2}{|c|}{$\begin{array}{c}\text { Gas Flow } \\
\text { sccm }\end{array}$} & \multirow[t]{2}{*}{$\begin{array}{l}\text { Pres. } \\
\text { mTorr }\end{array}$} & \multicolumn{2}{|c|}{$\begin{array}{c}\text { Etch rate } \\
\mathrm{nm} / \mathrm{min}\end{array}$} & \multirow[t]{2}{*}{$\begin{array}{l}\text { Selec- } \\
\text { tivity }\end{array}$} & \multicolumn{2}{|c|}{$\begin{array}{l}S / N \\
d B\end{array}$} \\
\hline & & ICP & $\mathrm{RF}$ & $\mathrm{O}_{2}$ & $\mathrm{SF}_{6}$ & & $\mathrm{nC}$ & $\mathrm{Cr}$ & & $\mathrm{nC}$ & $\mathrm{Cr}$ \\
\hline 1 & -110 & 200 & 100 & 10 & 10 & 10 & 34 & 0 & $135: 1$ & 31 & 12 \\
\hline 2 & -110 & 200 & 100 & 40 & 40 & 15 & 25 & 1 & $34: 1$ & 28 & 2 \\
\hline 3 & -110 & 500 & 150 & 10 & 10 & 15 & 97 & 1 & $99: 1$ & 40 & 0 \\
\hline 4 & -110 & 500 & 150 & 40 & 40 & 10 & 160 & 31 & $5: 1$ & 44 & -30 \\
\hline 5 & 20 & 200 & 150 & 10 & 40 & 10 & 47 & 6 & $8: 1$ & 33 & -16 \\
\hline 6 & 20 & 200 & 150 & 40 & 10 & 15 & 49 & 2 & $34: 1$ & 34 & -3 \\
\hline 7 & 20 & 500 & 100 & 10 & 40 & 15 & 95 & 4 & $25: 1$ & 40 & -12 \\
\hline 8 & 20 & 500 & 100 & 40 & 10 & 10 & $>180$ & 19 & $10: 1$ & 45 & -25 \\
\hline$\overline{\Delta_{\mathrm{nC}}}$ & 2.4 & 10.6 & 2.0 & 1.9 & 1.0 & 3.0 & & & & & \\
\hline$\Delta_{\mathrm{Cr}}$ & 10.3 & 15.5 & 6.5 & 10.2 & 9.6 & 11.7 & & & & & \\
\hline Opt.nc & 20 & 500 & 150 & 40 & 10 & 10 & $\sim 160$ & 16 & $10: 1$ & 50 & -29 \\
\hline Opt.sel & 20 & 500 & 100 & 10 & 10 & 10 & 80 & 1 & $109: 1$ & 42 & -6 \\
\hline Max & 50 & 800 & 200 & 50 & 0 & 10 & $\gg 390$ & 12 & $>32: 1$ & 52 & -19 \\
\hline
\end{tabular}

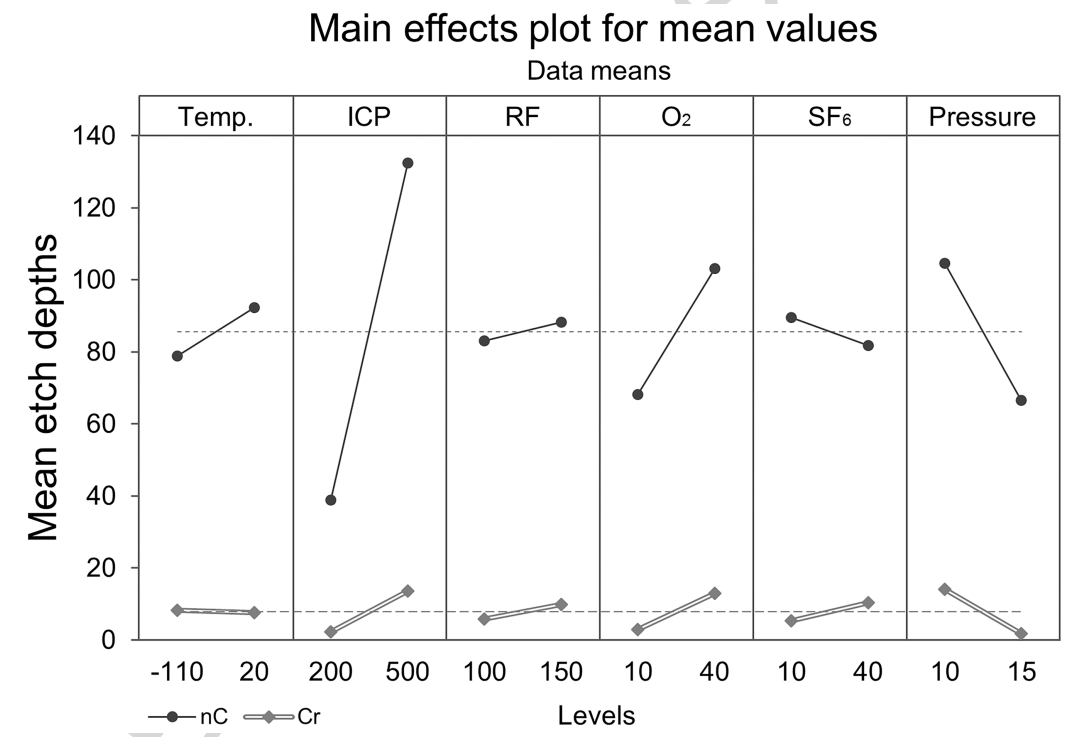

Figure 2: Response diagram of Taguchi experiments for both $\mathrm{nC}$ and $\mathrm{Cr}$ with inductively coupled plasma reactive ion etching. ICP power is the dominant parameter for $\mathrm{nC}$ etch rate.

rate within equipment parameter boundaries.

The recipe Opt.nC successfully increases $\mathrm{nC}$ etch rate as it was supposed to. The etch rate reached as high as $160 \mathrm{~nm} / \mathrm{min}$, similar to recipe 4, but the selectivity is better, 10:1 vs. 5:1. Opt.sel on the other hand raises the selectivity to 109:1 but still holds a good etch rate for nC. The maximized recipe shows incredible etch rate with over $390 \mathrm{~nm} / \mathrm{min}$ while keeping the selectivity acceptable. The exact etch rate could not be determined since the whole $\mathrm{nC}$ film was etched away during the etching run. 


\subsection{Raman analysis}

From the Raman spectrum, it is possible to identify two peaks determining the $\mathrm{sp}^{2}$ content in nanocarbon structure: disordered D-peak around $1350 \mathrm{~cm}^{-1}$ for chains, and graphitic G-peak around 1580-1600 $\mathrm{cm}^{-1}$ for rings [31]. The peaks were fitted with Lorentzian fit for D-peak and BWF for G-peak (Figure 1 in supplementary data).

The average $\mathrm{I}_{\mathrm{D}} / \mathrm{I}_{\mathrm{G}}$ ratio by height from seven samples is 0.71 (Min. 0.64, max. 0.83), indicating that the $\mathrm{nC}$ film has proportionally more $\mathrm{sp}^{2}$ rings than $\mathrm{sp}^{2}$ chains [31]. Since $\mathrm{sp}^{3}$-peak cannot be recognized from visible Raman spectra ( $\mathrm{sp}^{3} \mathrm{~T}$-peak around $1060 \mathrm{~cm}^{-1}$, visible in UV-Raman [36]), $[31,37]$ propose that the $\mathrm{sp}^{3}$ content can be estimated from $\mathrm{I}_{\mathrm{D}} / \mathrm{I}_{\mathrm{G}}$-ratio and position of $\mathrm{G}$-peak. Since average G-peak maximum in our data is $1569 \mathrm{~cm}^{-1}$ (Min. $1553 \mathrm{~cm}^{-1}$, max. $1575 \mathrm{~cm}^{-1}$ ), it is estimated that the average $\mathrm{sp}^{3}$-content is $50-60 \%$. [31] present their graphite amorphization trajectory with three-stages, and based on the Raman data above, our nanocarbon is in stage 3 (from a-C to ta-C) with high enough content of $\mathrm{sp}^{2}$-bonds to provide electrical conductivity, but also with high content of $\mathrm{sp}^{3}$-bonds to provide diamondlike properties.

A line scan was also taken from the $\mathrm{nC}$ film along $30 \mu \mathrm{m}$ line. The data shows spatial variation of D- and G-peak along the line. Based on the Raman spectra, $\mathrm{nC}$ has mostly $\mathrm{sp}^{2}$ rings with some areas dominated by chains. Since the $\mathrm{I}_{\mathrm{D}} / \mathrm{I}_{\mathrm{G}}$ ratio varies, also estimated $\mathrm{sp}^{3}$ content varies locally from less than $10 \%$ to as high as $90 \%$.

\subsection{Electrical characterization}

Resistance of thin film (500 nm) of $\mathrm{nC}$ was measured with a four point probe, and the average sheet resistance was calculated to be $63.4 \mathrm{k} \Omega / \square \pm 5.7 \mathrm{k} \Omega / \square$, which gives the material resistivity of $3.2 \Omega \mathrm{cm}$. This value is between graphene $\left(1.0^{*} 10^{-6} \Omega \mathrm{cm}[38]\right)$ and oxygen doped nanocrystalline diamond $\left(1.0^{*} 10^{8} \Omega \mathrm{cm}[39]\right)$, and similar to nitrogen doped nanocrystalline diamond $(1.0 \Omega \mathrm{cm}[39])$. Electrical conductivity proves that there is sizeable $\mathrm{sp}^{2}$ proportion in the film. $\mathrm{nC}$ resistivity causes high resistance in long distance electrodes, therefore metal layers were needed to enhance electrical conductivity. Few orders of magnitude lower resistivity would be sufficient, as is demonstrated by Picollo et al. by creating an all-carbon MEA from implanted graphitic carbon with resistivity of $1^{*} 10^{-3} \Omega \mathrm{cm}[18]$.

\subsection{Multielectrode array (MEA)}

Multiple versions of MEAs were fabricated in this study. The evolution of MEA material design and layer thicknesses can be seen in Table 3. Total of eight functional MEAs were fabricated, out of which three were made from metal, one completely from nanocarbon and four from combination of these two. The resistance is measured from four reference electrodes and averaged. Two commercial MED64 MED-P515A MEAs were also measured for comparison. 
Table 3: Different MEA chip array materials and their reference wire electrical resistance. Two MED64 MEAs are commercial products (MED-P515A), other MEAs are fabricated in this research.

\begin{tabular}{|c|c|c|c|c|c|c|}
\hline $\begin{array}{l}\text { MEA } \\
\text { id }\end{array}$ & Substrate & $\mathrm{SiO}_{2}$ & $\begin{array}{l}\text { Layers } \\
1 \mathrm{st}\end{array}$ & 2nd & Insulation & $\begin{array}{c}\text { Resistance } \\
\Omega\end{array}$ \\
\hline Metal 1 & Pyrex & - & $\mathrm{Al}, 300 \mathrm{~nm}$ & - & SU-8, 2000.5 & 6.4 \\
\hline Metal 2 & Pyrex & - & $\mathrm{Cr}, 50 \mathrm{~nm}$ & $\mathrm{Pt}, 50 \mathrm{~nm}$ & SiOx, $100 \mathrm{~nm}$ & 92 \\
\hline $\mathrm{nC}$ & Silicon & $300 \mathrm{~nm}$ & $\mathrm{nC}, 100 \mathrm{~nm}$ & - & SU-8, 2000.5 & $1.6^{*} 10^{6}$ \\
\hline Metal-nC 1 & Silicon & $300 \mathrm{~nm}$ & $\mathrm{nC}, 500 \mathrm{~nm}$ & Al, $100 \mathrm{~nm}$ & SU-8, 2000.5 & 29 \\
\hline Metal-nC 2 & Silicon & $300 \mathrm{~nm}$ & $\mathrm{nC}, 500 \mathrm{~nm}$ & $\mathrm{Al}, 300 \mathrm{~nm}$ & SU-8, 2000.5 & 6.5 \\
\hline Metal-nC 3 & Silicon & $300 \mathrm{~nm}$ & $\mathrm{nC}, 100 \mathrm{~nm}$ & $\mathrm{Cr}, 50 \mathrm{~nm}$ & SiOx, 200 nm & 6400 \\
\hline Metal-nC 4 & Silicon & $300 \mathrm{~nm}$ & $\mathrm{nC}, 100 \mathrm{~nm}$ & $\mathrm{Cr}, 100 \mathrm{~nm}$ & SiOx, $200 \mathrm{~nm}$ & 5700 \\
\hline MED64-1 & Polymer & - & ITO & Gold & Acrylate resin & 510 \\
\hline MED64-2 & Pyrex & - & ITO & Pt Black & Acrylate resin & 460 \\
\hline
\end{tabular}

As can be seen from Table 3, the metal-only MEAs give lower resistance $(6.4 \Omega$ and $92 \Omega)$ than the commercial MED64 MED-P515A MEAs $(511 \Omega$ and $460 \Omega$ ). In commercial MED-P515A, the conductive wiring is made from transparent ITO (indium tin oxide) and recording electrodes (which are in contact with studied sample) are coated with platinum black. Passivation layer on top of conductive wiring is acrylate resin [32] to prevent short circuits. The MEA named "nC" has only nanocarbon as conductive wiring, and it has very high reference electrode resistance, (1.6 $\mathrm{M} \Omega)$.

A combination with carbon recording electrodes and metal wiring, named Metal-nC 1, 2, 3 and 4, were fabricated, and they had resistances of $28.5 \Omega, 6.5 \Omega, 6400 \Omega$ and $5700 \Omega$, respectively. The metal-carbon electrodes have metal on top of carbon for enhanced electrical conduction, but the metal is removed from the recording electrode pads, which will be in contact with the neurons.

The layout of the MEA can be seen in Figure 3a. The leftmost image shows the Metal-nC 4 MEA with a quartz ring glued on top to serve as a culture well. Middle image shows the recording electrodes (50x50 $\mu \mathrm{m}^{2}$ squares) located in the center of the MEA with $\mathrm{nC}$ exposed. Rightmost image shows one individual recording electrode with exposed $\mathrm{nC}$ pad and $\mathrm{Cr}$ metal wiring.

\subsection{Neurocompatibility}

To assess neurocompatibility of $\mathrm{nC}$ substrate we plated dissociated neuronal cultures on either $\mathrm{nC}$ or control glass surfaces. Representative immunostainings of these cultures at DIV7 are shown in Figure 3b and c. Anti-MAP2 and anti-GFAP antibodies recognize neuron-specific and glia-specific cytoskeletal proteins, respectively. MAP2-GFAP immunostainings, similar to the one shown in Figure 3b, demonstrated that overall culture density, as well as the morphology of neurons was comparable in cultures grown on either substrate. Figure 3c shows KCC2-NeuN immunostaining. NeuN is a neuron-specific nuclear antigen, whereas anti-KCC2 antibodies recognize K-Cl co-transporter $\mathrm{KCC} 2$, used here as a marker of neuronal maturation. Immunostaining with the 
neuron specific markers $\mathrm{NeuN}$ and $\mathrm{KCC} 2$ show no difference between $\mathrm{nC}$ and glass substrates. As KCC2 is particularly sensitive to pathological condition, these results indicate that neurons growing on $\mathrm{nC}$ are healthy with no signs of damage as compared to the neurons cultured on glass. KCC2-NeuN immunostainings demonstrate that $\mathrm{nC}$ substrate supports growth and maturation of neurons. In conclusion, we found that at DIV7 neurons growing on $\mathrm{nC}$ substrate are at least equally viable as the ones growing on glass.

\section{A}

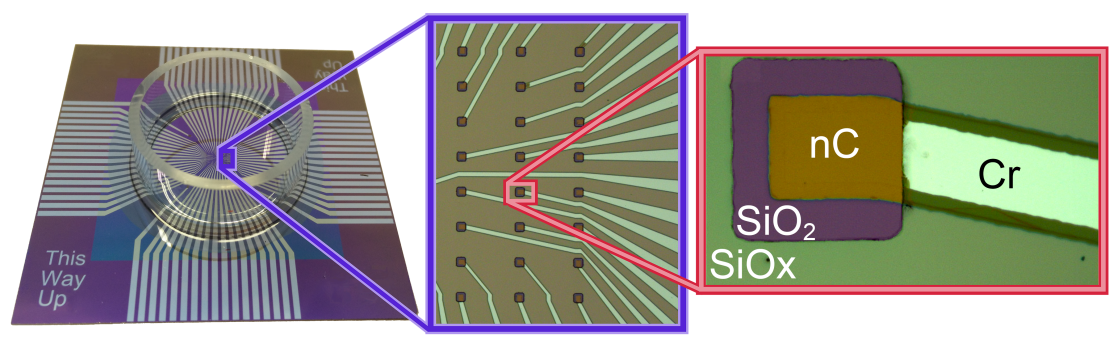

B

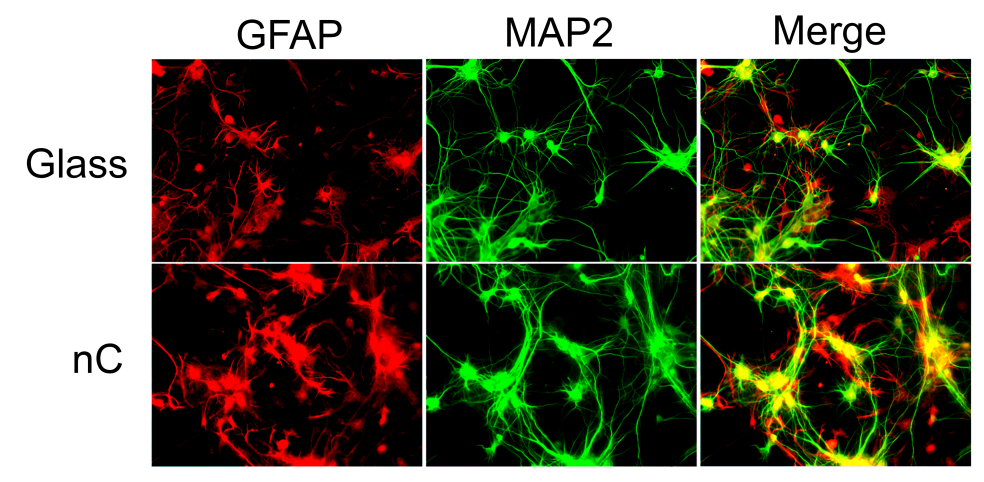

C

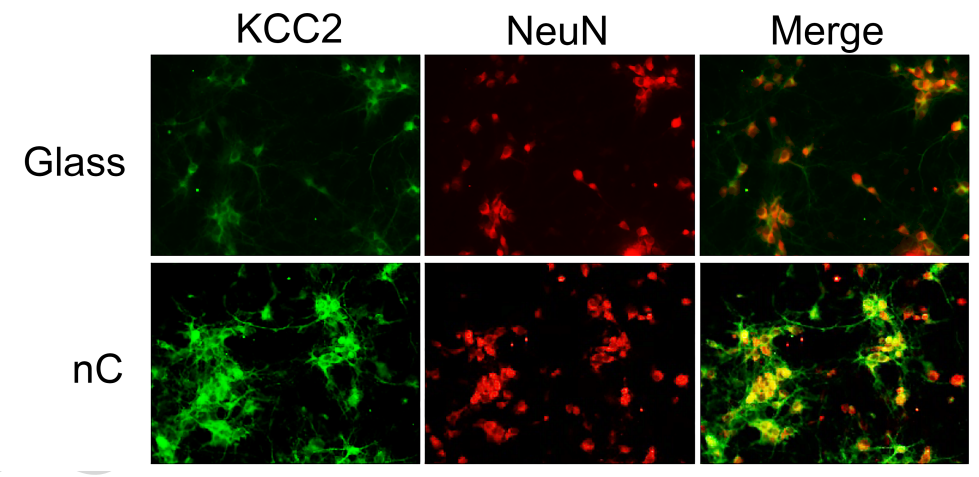

Figure 3: (a) The $\mathrm{nC}$ MEA is $5 \times 5 \mathrm{~cm}^{2}$ chip with 64 recording electrodes at the center surrounded by round quartz culture well. Rightmost picture shows an individual recording electrode with exposed nC under chromium. The dimensions of the $\mathrm{nC}$ pad are $50 \times 50 \mu \mathrm{m}^{2} . \mathrm{SiO}_{2}$ and $\mathrm{SiOx}$ are silicon oxide bottom (thermal) and top (PEVCD) insulation layers, respectively. (b) Hippocampal neuron culturing on $\mathrm{nC}$ and glass substrate with anti-MAP2 (red) and anti-GFAP (green) immunostaining. (c) Immunostaining by anti-KCC2 (green) and anti-NeuN (red) antibodies.

Organotypic hippocampal slices were cultivated to study the biocompatibility and signal detection properties of $\mathrm{nC}$ MEAs. The results were compared with commercially available MED64 MED-P515A MEA (MED64-2 in Table 3, from here on referred to as P515A). Before electro- 
physiological recordings, the slice cultures were imaged to detect the orientation of the recording electrodes and to observe the slice quality. Under the bright field, the slices grown on nC MEA had sharp edges, even surface and well preserved hippocampal morphology (Figure 4a), similar to the slices grown on the commercial P515A MEA (Figure 4b). After recordings, the slice cultures were stained with propidium iodide (PI), to detect the damaged cells and verify the slice viability. The survival of cells in the cultures was similar with nC and P515A MEAs (Figure 4c and d) since the quantification of PI-stained cells in the slices did not show difference between the used MEAs. Thus, with the tested methods nC MEAs provided good biocompatibility for hippocampal slice culturing.

Network activity of the hippocampal slice cultures was recorded at DIV8. These organotypic slices present spontaneous neuronal bursting activity, with alternating pattern of silent periods and hypersynchronous population bursts, which propagate through different regions of the hippocampus (Figure 4e and f). The hypersynchronous discharges were detected from electrodes located in CA3-CA1 areas with 7xRMS noise threshold. nC MEA (Metal-nC 3) acquired these events with $0.07 \pm 0.004 \mathrm{mV}$ peak amplitude (mean $\pm \mathrm{SEM}$ ), when same events captured by P515A had a greater peak amplitude $0.25 \pm 0.020 \mathrm{mV},(\mathrm{p}<0.05)$. The RMS noise for all channels was calculated from $20 \mathrm{~s}$ long recording with no bursting activity (Figure $4 \mathrm{~g}$ and $\mathrm{h}$ ). In RMS noise, there was no significant difference between $\mathrm{nC}$ and P515A MEAs $(\mathrm{nC} 9.5 \pm 0.9 \mu \mathrm{V} ; \mathrm{P} 515 \mathrm{~A} 10.5$ $\pm 0.5 \mu \mathrm{V}, \mathrm{p}>0.05)$. Signal-to-noise ratio was calculated for channels at CA3-CA1 individually by dividing the detected peak amplitudes in hypersynchronous bursts by RMS noise. With this method, signal-to-noise ratio for $\mathrm{nC}$ was $13 \pm 1.4$ and for P515A $59 \pm 7.0$. With less sensitive event detection the signal-to-noise ratio of $\mathrm{nC}$ MEA was approximately $1 / 4$ when compared to the P515A. The difference between $\mathrm{S} / \mathrm{N}$ ratio is mostly because of the high difference in electrode surface area; nC MEA is mostly flat with small nanoroughness, whereas P515A MEA has rough platinum black on the electrodes resulting in different detection area and different cell attachment, which are also the advantages of 3D carbon nanotube surfaces (reviewed in [40]). Besides, the power spectrum (Figure 4i) from the synchronous activity shows that nC MEA detected the slow components of the activity, but the detection of higher frequencies was weaker when compared to P515A. To confirm that the recorded activity was of neuronal origin, $2 \mathrm{nM}$ tetrodotoxin (TTX) was added to the culture media to block voltage-gated $\mathrm{Na}+$-channels and thus, the generation of action potential. Accordingly, TTX application resulted in complete loss of electrical activity (Figure 2 in supplementary data). 
A

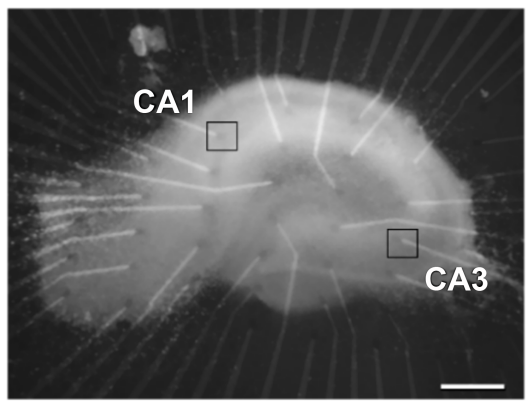

C

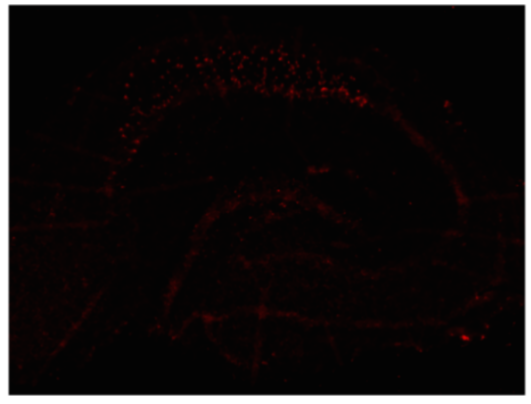

E
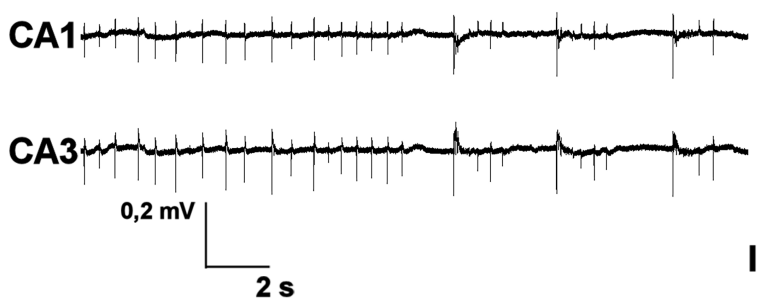

G

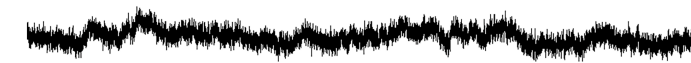

H

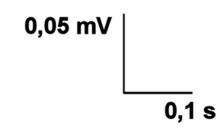

M.
B

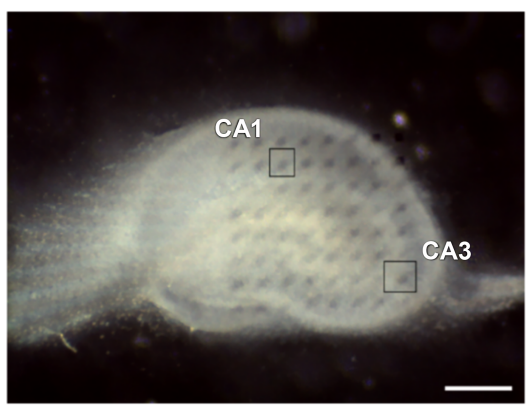

D

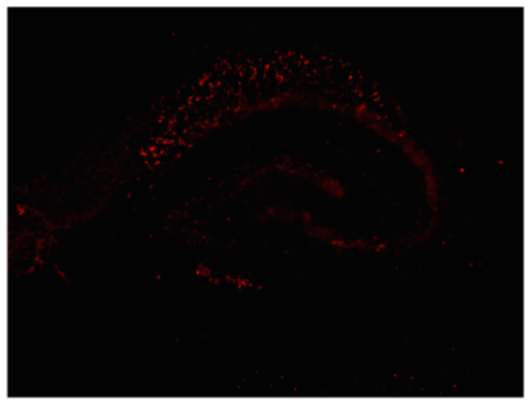

F
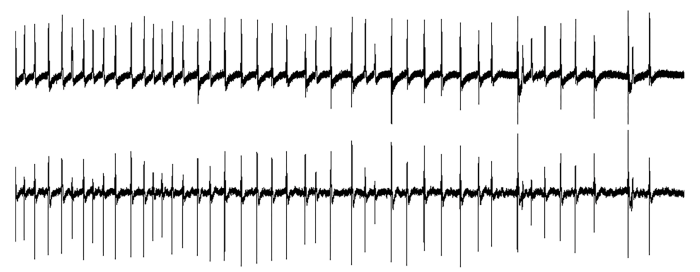

I $2.5 \times 10^{-5}$

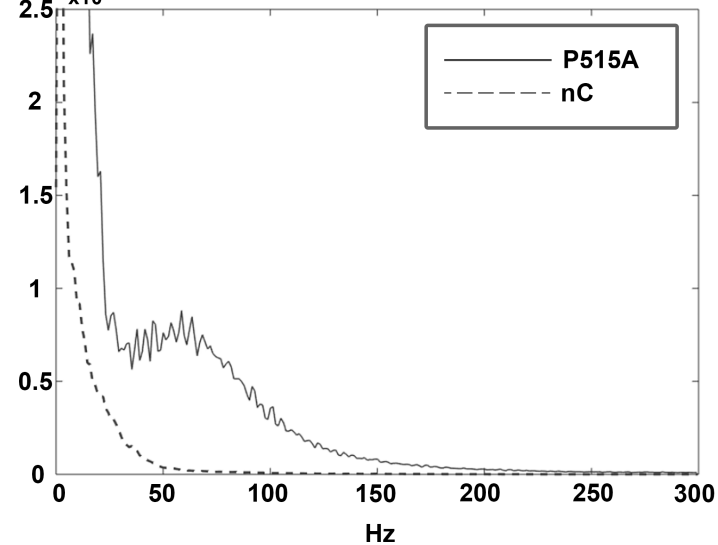

Figure 4: Survival and electrophysiological activity in cultured hippocampal slices on Metal-nC 3 (A, C, E, G) and P515A MEAs (B, D, F, H). (A and B) Bright field images from DIV8 slices. Scale bar $450 \mu \mathrm{m}$. (C and D) PI staining from 11DIV slices. (E and F) Spontaneous, synchronous bursts of electrical activity recorded from CA1 and CA3 of DIV8 slices. ( $\mathrm{G}$ and H) Quiet period from the recording to show the baseline and calculate the RMS noise level. (I) Power spectra from activity recorded in CA3. 


\section{Conclusions}

Patternability and biocompatibility along with electrical conductivity are crucial properties needed for multielectrode arrays and other devices that operate at the electronics/biology interface. Patterning experiments for material as hard as diamond will provide essential information for patterning of other carbonaceous materials. In this study, we etched nanocarbon with two different plasma etching methods, RIE and ICP-RIE. The optimized RIE recipe produced an etch rate of $14 \mathrm{~nm} / \mathrm{min}$ and selectivity of 40:1. The optimized ICP-RIE recipe produced an etch $\mathrm{nC}$ rate of $160 \mathrm{~nm} / \mathrm{min}$ and selectivity of 109:1. The experiment with Taguchi method indicates that the gas selection is critical, but the flow of fresh gas is not. The study shows that fluorine based chemistry works in carbon etching, but the presence of oxygen is more crucial. The most important parameters for high etch rate were plasma power and gas pressure. The acquired etch rates and selectivities are very good and are suitable for most thin carbon film etching processes (our thickest nC films were $500 \mathrm{~nm}$ ).

A thin film of nanocarbon was patterned and a $8 \times 8$ multielectrode array was fabricated with metal wiring. The electrode resistance and metal-nanocarbon contact can be further optimized with different metal selection. Good alternatives would be titanium and tungsten which both create carbide and can therefore form a strong bond with carbon film.

Nanocarbon proved to support culturing of dissociated hippocampal neurons with similar viability as the glass substrate. In addition, nanocarbon MEAs were suitable for culturing organotypic hippocampal slices, which maintained their viability and morphology. Electrophysiological recordings indicated that neuronal network grown on the $\mathrm{nC}$ MEA acquired mature synchronous activity. The RMS noise in these experiments was comparable with the platinum black electrodes used as a reference, as well as previously described flat electrodes with graphene coatings [41, 42]. S/N ratios with small $(10-20 \mu \mathrm{m})$ graphene coated electrodes and dispersed neuronal cultures have been in the same range as in our setup [41, 42]. In this perspective nC MEA shows promising characteristics in signal detection and is comparable to other carbon based innovations. However, due to the still low $\mathrm{S} / \mathrm{N}$ ratio, population spikes with smaller amplitude and higher frequency were not detected. Therefore the sensitivity of $\mathrm{nC}$ MEA is not yet at the same level as with the commercial MED64 P515A MEAs, mainly because nC MEAs have high impedance due to a small recording electrode surface area compared to the commercial MEAs, which use rough platinum black. This will be a topic for further experiments, but the work presented here shows a promise in bioelectrical sensing due to nanocarbons patternability, electrical conductivity, and biocompatibility with neuronal cultures and slices. 


\section{Acknowledgements}

The research was carried out in Micronova Centre for micro and nanotechnology, Aalto University. Neuronal culture and brain slice experiments were done in University of Helsinki, Neuroscience center and Department of Veterinary Biosciences. Nanocarbon sputtering was done in CAPST, Sungkyunkwan University, Republic of Korea.

Policy and etchics

Conflicts of interest: none

Funding

Financial support was given by Aalto University School of Chemical technology Doctoral program.

\section{References}

[1] R. L. McCreery, "Advanced carbon electrode materials for molecular electrochemistry," Chem. Rev, vol. 108, no. 7, pp. 2646-2687, 2008.

[2] K. Kinoshita, Carbon: electrochemical and physicochemical properties. John Wiley Sons, New York, NY, 1988.

[3] A. Pandolfo and A. Hollenkamp, "Carbon properties and their role in supercapacitors," Journal of power sources, vol. 157, no. 1, pp. 11-27, 2006.

[4] H. S. Myung, Y. S. Park, M. J. Jung, B. Hong, and J. G. Han, "Synthesis and mechanical properties of amorphous carbon films by closed-field unbalanced magnetron sputtering," Materials Letters, vol. 58, no. 9, pp. 1513-1516, 2004.

[5] Y. S. Park, H. S. Myung, J. G. Han, and B. Hong, "Tribological properties of amorphous carbon thin films grown by magnetron sputtering method," Surface and Coatings Technology, vol. 180, pp. 218-221, 2004.

[6] J. Robertson, "Electronic and atomic structure of diamond-like carbon," Semiconductor science and technology, vol. 18, no. 3, p. S12, 2003.

[7] S. I. Kim, B. B. Sahu, S. E. Kim, A. Ali, E. H. Choi, and J. G. Han, "Controlling conductivity of carbon film for l-929 cell biocompatibility using magnetron sputtering plasmas," J. Mater. Chem. B, vol. 3, pp. 3267-3278, 2015. 
[8] M. Kumar, J. X. Piao, S. B. Jin, J. H. Lee, S. Tajima, M. Hori, and J. G. Han, "Low temperature plasma processing for cell growth inspired carbon thin films fabrication," Archives of Biochemistry and Biophysics, vol. 605, pp. 41 - 48, 2016. Special Issue: Low-temperature plasma in biology and medicine.

[9] S. Ranganathan, R. Mccreery, S. M. Majji, and M. Madou, "Photoresist-derived carbon for microelectromechanical systems and electrochemical applications," Journal of the Electrochemical Society, vol. 147, no. 1, pp. 277-282, 2000.

[10] L. Amato, A. Heiskanen, C. Caviglia, F. Shah, K. Zór, M. Skolimowski, M. Madou, L. Gammelgaard, R. Hansen, E. G. Seiz, M. Ramos, T. R. Moreno, A. Martínez-Serrano, S. S. Keller, and J. Emnéus, "Pyrolysed 3d-carbon scaffolds induce spontaneous differentiation of human neural stem cells and facilitate real-time dopamine detection," Advanced Functional Materials, vol. 24, no. 44, pp. 7042-7052, 2014.

[11] G. P. Keeley, N. McEvoy, H. Nolan, S. Kumar, E. Rezvani, M. Holzinger, S. Cosnier, and G. S. Duesberg, "Simultaneous electrochemical determination of dopamine and paracetamol based on thin pyrolytic carbon films," Analytical Methods, vol. 4, no. 7, pp. 2048-2053, 2012.

[12] Š. Meškinis, V. Kopustnikas, K. Šlapikas, R. Gudaitis, A. Guobienè, and S. Tamulevičius, "Oxygen ion beam etching of diamond like carbon films," Materials Science (Medžiagotyra), vol. 13 , no. $4,2007$.

[13] H. Oka, K. Shimono, R. Ogawa, H. Sugihara, and M. Taketani, "A new planar multielectrode array for extracellular recording: application to hippocampal acute slice," Journal of neuroscience methods, vol. 93, no. 1, pp. 61-67, 1999.

[14] Y. Berdichevsky, H. Sabolek, J. B. Levine, K. J. Staley, and M. L. Yarmush, "Microfluidics and multielectrode array-compatible organotypic slice culture method," Journal of neuroscience methods, vol. 178, no. 1, pp. 59-64, 2009.

[15] K. Najafi and K. D. Wise, "An implantable multielectrode array with on-chip signal processing," IEEE Journal of Solid-State Circuits, vol. 21, no. 6, pp. 1035-1044, 1986.

[16] A. Branner and R. A. Normann, "A multielectrode array for intrafascicular recording and stimulation in sciatic nerve of cats," Brain research bulletin, vol. 51, no. 4, pp. 293-306, 2000.

[17] Z. Fekete, "Recent advances in silicon-based neural microelectrodes and microsystems: a review," Sensors and Actuators B: Chemical, vol. 215, pp. 300 - 315, 2015.

[18] F. Picollo, A. Battiato, E. Bernardi, M. Plaitano, C. Franchino, S. Gosso, A. Pasquarelli, E. Carbone, P. Olivero, and V. Carabelli, "All-carbon multi-electrode array for real-time in vitro measurements of oxidizable neurotransmitters," Scientific reports, vol. 6, p. 20682, 2016. 
[19] J. Dragas, V. Viswam, A. Shadmani, Y. Chen, R. Bounik, A. Stettler, M. Radivojevic, S. Geissler, M. E. J. Obien, J. Müller, et al., "In vitro multi-functional microelectrode array featuring 59760 electrodes, 2048 electrophysiology channels, stimulation, impedance measurement, and neurotransmitter detection channels," IEEE journal of solid-state circuits, vol. 52, no. 6, pp. 1576-1590, 2017.

[20] A. F. Johnstone, G. W. Gross, D. G. Weiss, O. H.-U. Schroeder, A. Gramowski, and T. J. Shafer, "Microelectrode arrays: A physiologically based neurotoxicity testing platform for the 21st century," NeuroToxicology, vol. 31, no. 4, pp. 331 - 350, 2010.

[21] E. Claverol-Tinture, M. Ghirardi, F. Fiumara, X. Rosell, and J. Cabestany, "Multielectrode arrays with elastomeric microstructured overlays for extracellular recordings from patterned neurons," Journal of neural engineering, vol. 2, no. 2, p. L1, 2005.

[22] V. Jokinen, P. Sakha, P. Suvanto, C. Rivera, S. Franssila, S. E. Lauri, and H. J. Huttunen, "A microfluidic chip for axonal isolation and electrophysiological measurements," Journal of Neuroscience Methods, vol. 212, no. 2, pp. 276 - 282, 2013.

[23] E. Babich, A. Callegari, F. Doany, and S. Purushothaman, "Sputter deposition of hydrogenated amorphous carbon film and applications thereof," Nov. 3 1998. US Patent 5,830,332.

[24] M. Massi, J. Ocampo, H. Maciel, K. Grigorov, C. Otani, L. Santos, and R. D. Mansano, "Plasma etching of DLC films for microfluidic channels," Microelectronics journal, vol. 34, no. 5, pp. 635-638, 2003.

[25] G. McLane and J. Flemish, "High etch rates of $\mathrm{SiC}$ in magnetron enhanced $\mathrm{SF}_{6}$ plasmas," Applied physics letters, vol. 68, no. 26, pp. 3755-3757, 1996.

[26] R. Legtenberg, H. Jansen, M. de Boer, and M. Elwenspoek, "Anisotropic reactive ion etching of silicon using $\mathrm{SF}_{6} / \mathrm{O}_{2} / \mathrm{CHF}_{3}$ gas mixtures," Journal of The Electrochemical Society, vol. 142, no. 6, pp. 2020-2028, 1995.

[27] E. Kaivosoja, S. Sainio, J. Lyytinen, T. Palomäki, T. Laurila, S. I. Kim, J. G. Han, and J. Koskinen, "Carbon thin films as electrode material in neural sensing," Surface and Coatings Technology, vol. 259, pp. 33 - 38, 2014. The 9th Asian-European International Conference on Plasma Surface Engineering.

[28] K.-H. Tseng, Y.-F. Shiao, R.-F. Chang, and Y.-T. Yeh, "Optimization of microwave-based heating of cellulosic biomass using taguchi method," Materials, vol. 6, no. 8, pp. 3404-3419, 2013.

[29] J. Antony, "Taguchi or classical design of experiments: a perspective from a practitioner," Sensor Review, vol. 26, no. 3, pp. 227-230, 2006. 
[30] J.-H. Boo, H. K. Park, K. H. Nam, and J. G. Han, "High rate deposition of poly-Si thin films at low temperature using a new designed magnetron sputtering source," Surface and Coatings Technology, vol. 131, no. 1, pp. 211-215, 2000.

[31] A. C. Ferrari and J. Robertson, "Interpretation of raman spectra of disordered and amorphous carbon," Physical review B, vol. 61, no. 20, p. 14095, 2000.

[32] Alpha MED Scientific, "MED Probe." http://www.med64.com/products/medprobe.html, January 2015.

[33] O. Llano, S. Smirnov, S. Soni, A. Golubtsov, I. Guillemin, P. Hotulainen, I. Medina, H. G. Nothwang, C. Rivera, and A. Ludwig, "Kcc2 regulates actin dynamics in dendritic spines via interaction with $\beta$-pix," The Journal of Cell Biology, vol. 209, no. 5, pp. 671-686, 2015.

[34] L. Stoppini, P.-A. Buchs, and D. Muller, "A simple method for organotypic cultures of nervous tissue," Journal of neuroscience methods, vol. 37, no. 2, pp. 173-182, 1991.

[35] G. Sandhu and W. Chu, "Reactive ion etching of diamond," Applied physics letters, vol. 55, no. 5, pp. 437-438, 1989.

[36] A. C. Ferrari and J. Robertson, "Resonant raman spectroscopy of disordered, amorphous, and diamondlike carbon," Physical Review B, vol. 64, no. 7, p. 075414, 2001.

[37] A. C. Ferrari and J. Robertson, "Raman spectroscopy of amorphous, nanostructured, diamond-like carbon, and nanodiamond," Philosophical Transactions of the Royal Society of London A: Mathematical, Physical and Engineering Sciences, vol. 362, no. 1824, pp. 2477$2512,2004$.

[38] J.-H. Chen, C. Jang, S. Xiao, M. Ishigami, and M. S. Fuhrer, "Intrinsic and extrinsic performance limits of graphene devices on SiO2," Nature nanotechnology, vol. 3, no. 4, pp. 206-209, 2008.

[39] K. Teii and T. Ikeda, "Conductive and resistive nanocrystalline diamond films studied by raman spectroscopy," Diamond and Related Materials, vol. 16, no. 4-7, pp. 753 - 756, 2007.

[40] Y. Hanein and L. Bareket-Keren, "Carbon nanotube-based multi electrode arrays for neuronal interfacing: progress and prospects," Frontiers in Neural Circuits, vol. 6, p. 122, 2013.

[41] D. Kireev, S. Seyock, J. Lewen, V. Maybeck, B. Wolfrum, and A. Offenhäusser, "Graphene multielectrode arrays as a versatile tool for extracellular measurements," Advanced Healthcare Materials, vol. 6, no. 12, p. 1601433. 
[42] X. Du, L. Wu, J. Cheng, S. Huang, Q. Cai, Q. Jin, and J. Zhao, "Graphene microelectrode arrays for neural activity detection," Journal of biological physics, vol. 41, no. 4, pp. 339-347, 2015.

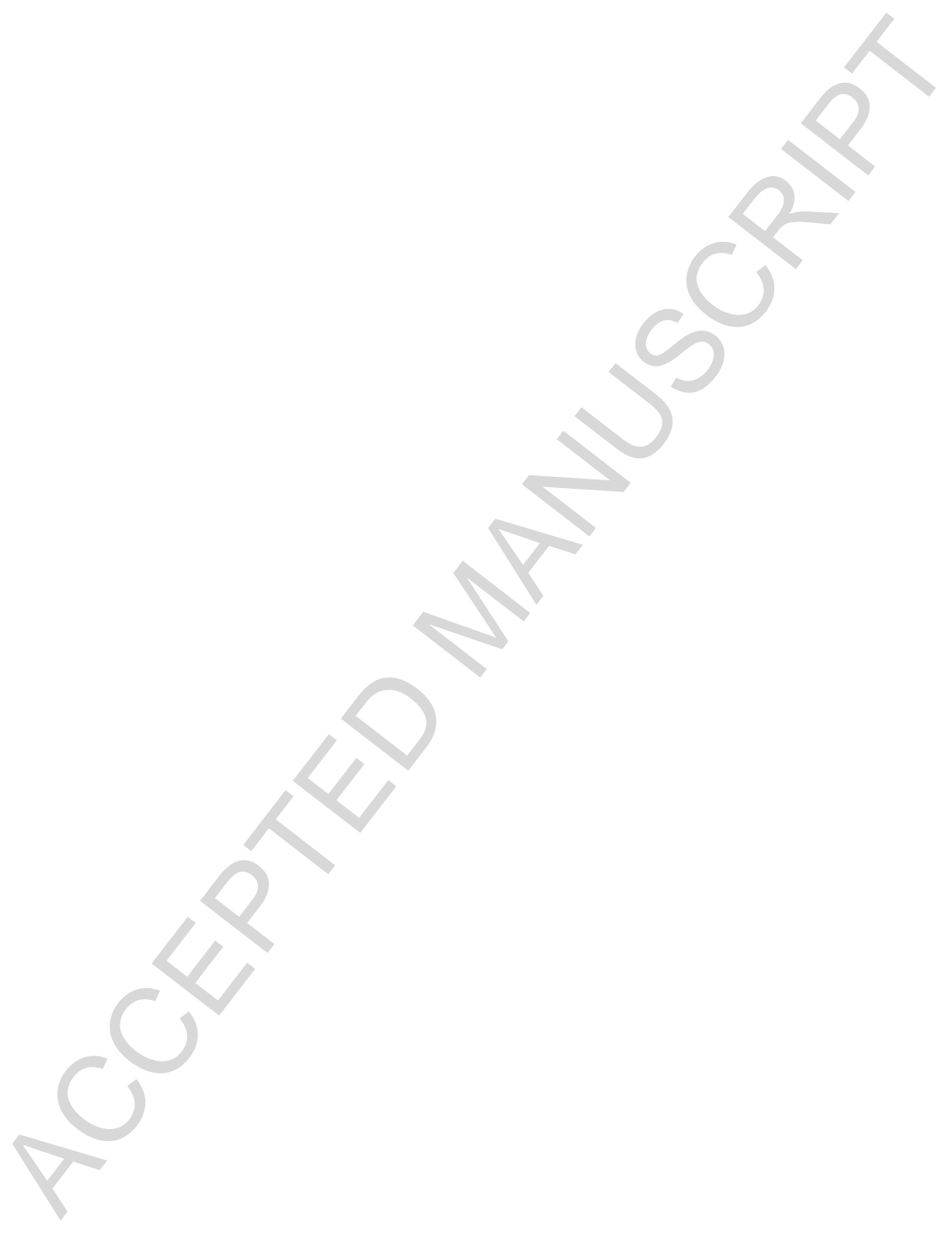




\section{Graphical abstract}
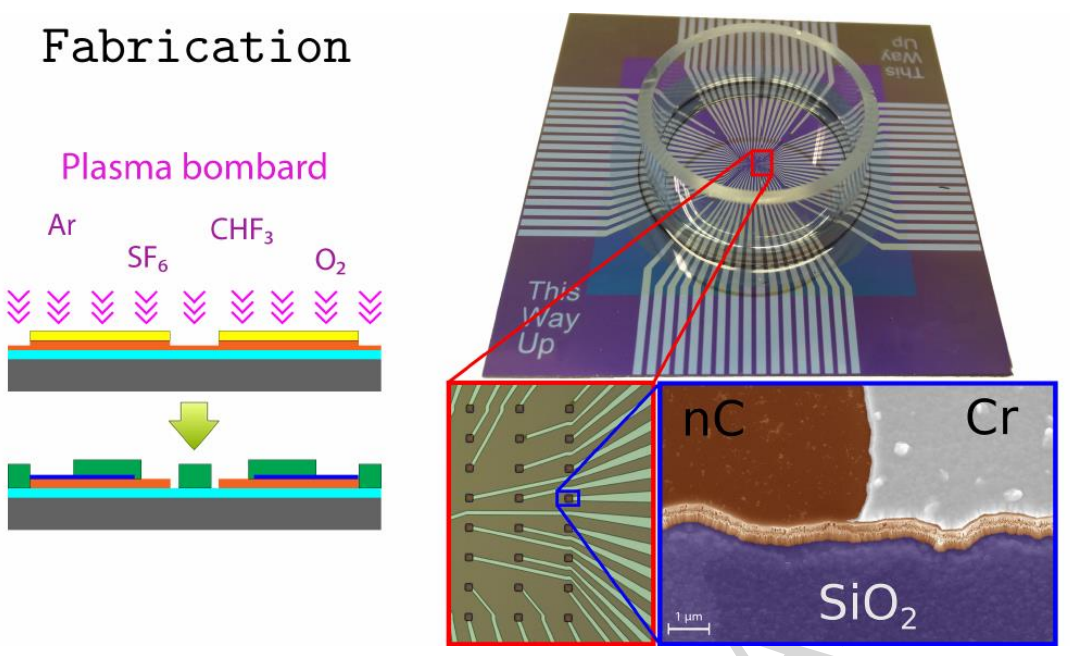

Measurement
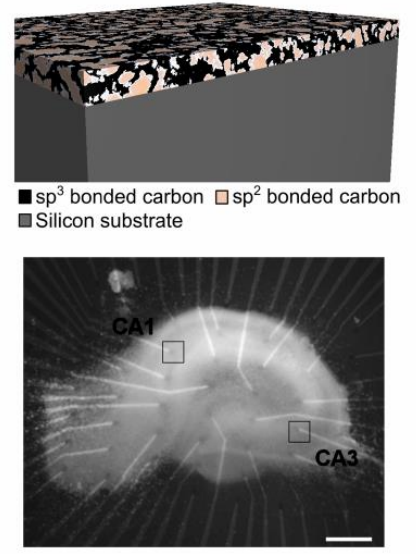


\section{Highlights}

\#1 Plasma etching optimization for nanocarbon thin film with Taguchi-method

\#2 Successful fabrication of multielectrode array from nanocarbon thin film

\#3 Nanocarbon thin film supports neuronal culturing with similar viability as glass

\#4 Nanoarbon multielectrode array allowed electrophysiological recordings

\#5 Use of carbon for bioelectrical sensing is an attractive alternative to metals 
Main effects plot for mean values

Data means

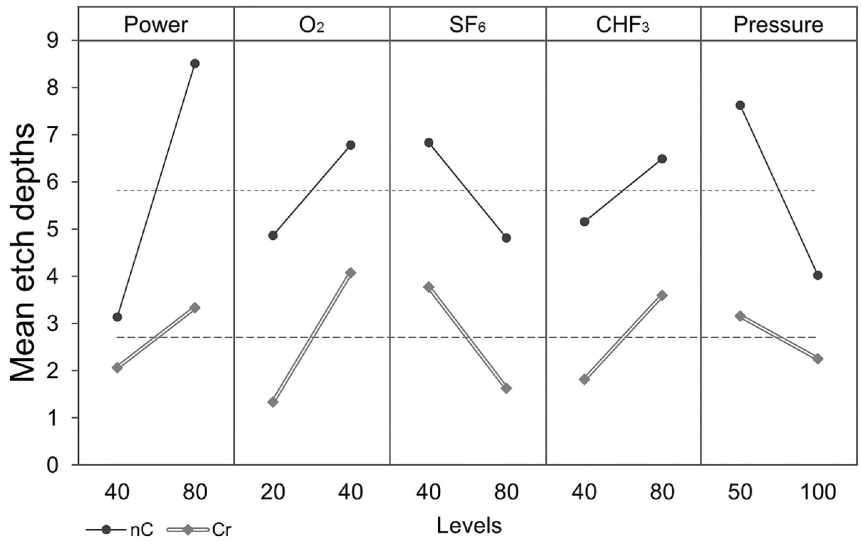

Figure 1 
Main effects plot for mean values

Data means

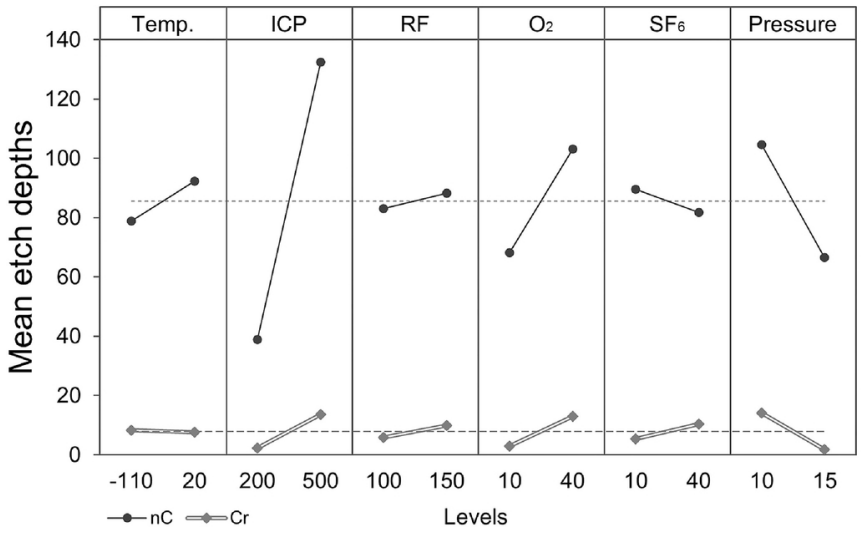

Figure 2 
A

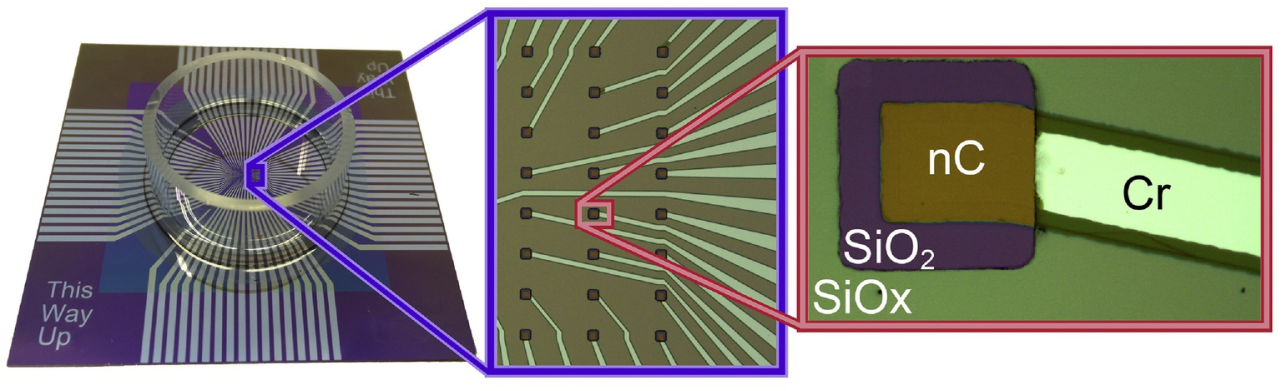

B

\section{Glass}
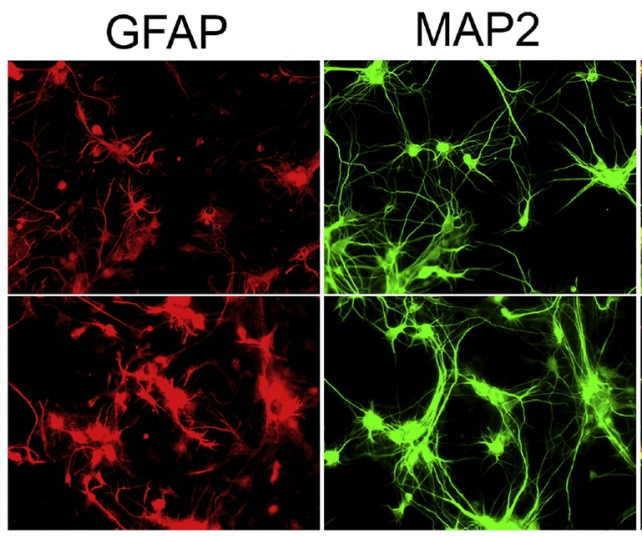

Merge

C

$\mathrm{KCC} 2$

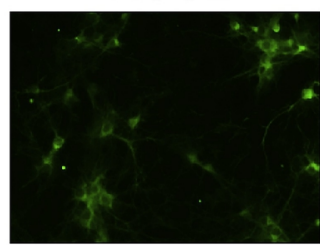

Glass

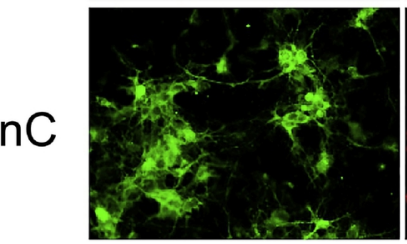

NeuN
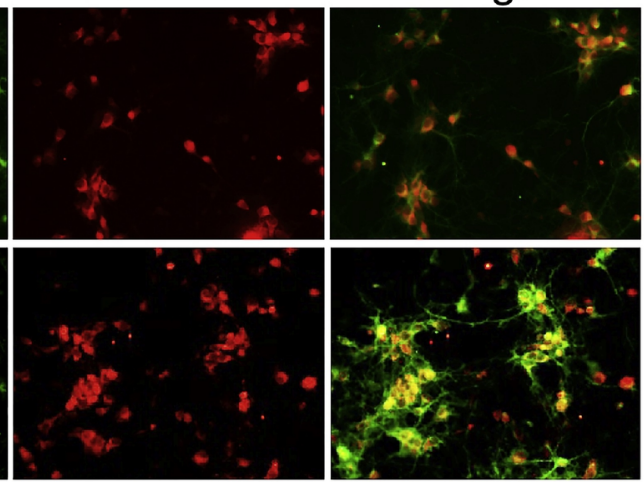

Figure 3 
A

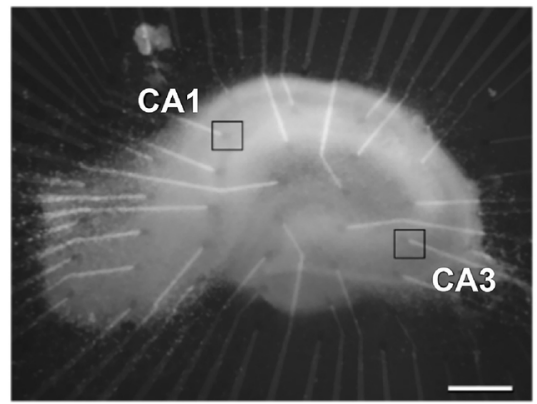

C

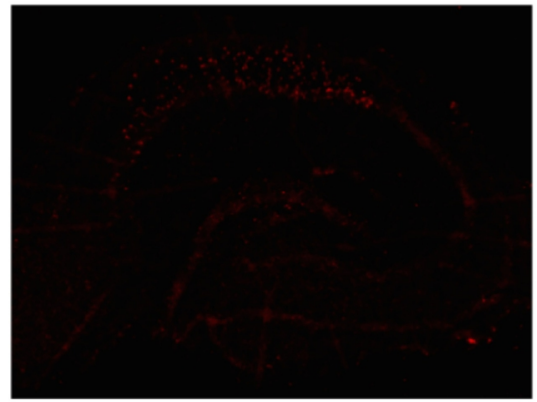

E

CA1

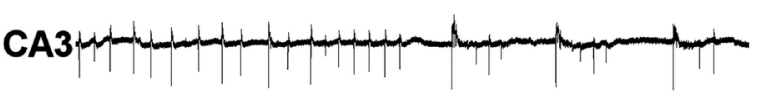

$0,2 \mathrm{mV}$

$2 \mathrm{~s}$

G

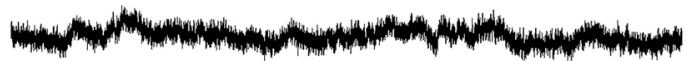

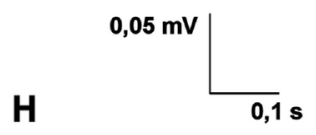

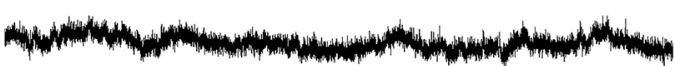

\section{F}
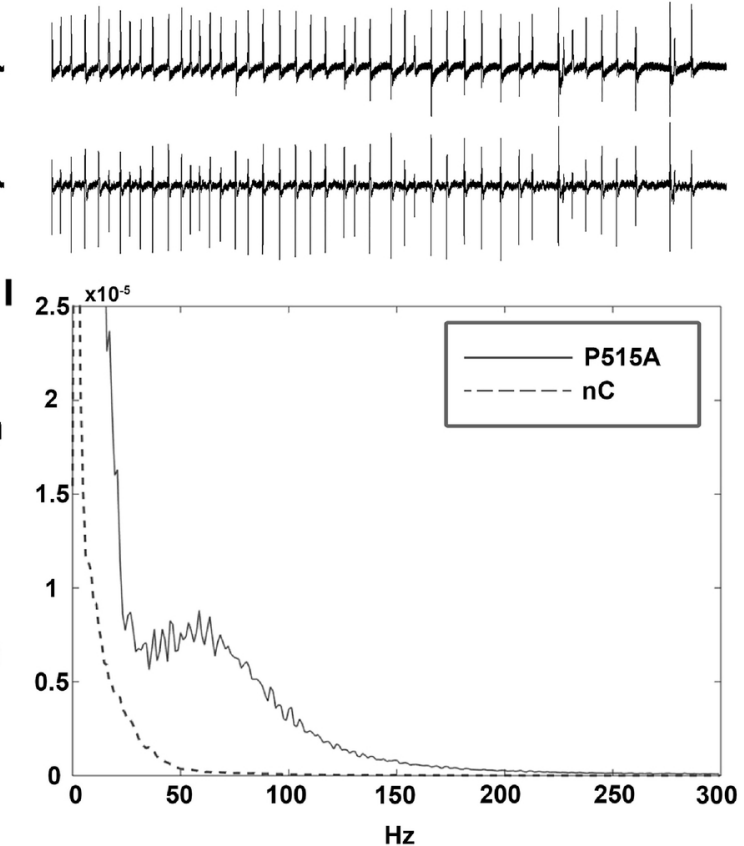

Figure 4 
(A)

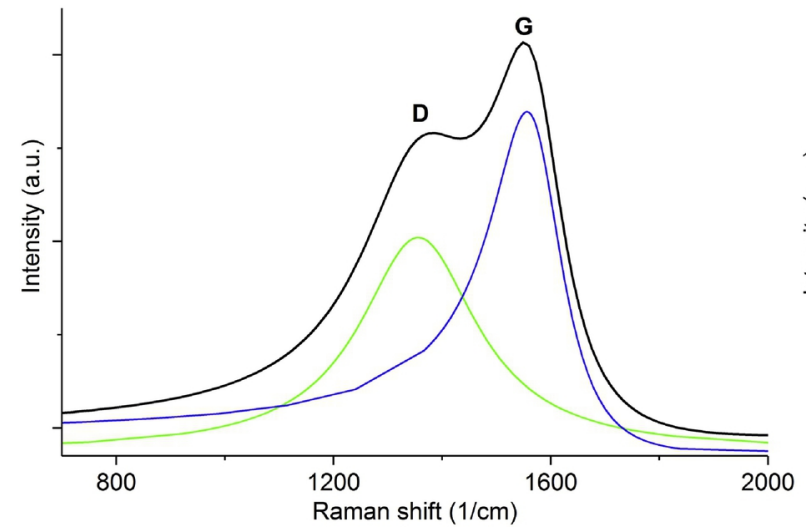

(B)

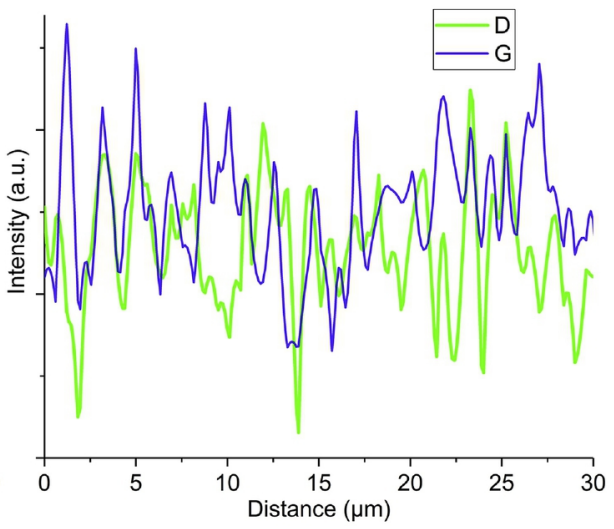

Figure 5 


\section{Spontaneous activity DIV8}

CA1

$0,1 \mathrm{mV}$ $10 \mathrm{~s}$

CA3

Figure 6 